\title{
Autonomia e Flexibilidade Curricular como Instrumentos Gestionários. O Caso de Portugal
}

\section{Curricular Autonomy and Flexibility as Management Tools. The Case of Portugal}

\author{
Sofia Silva *, Nuno Fraga \\ Universidade da Madeira, Portugal
}

\section{DESCRIPTORES:}

Política educativa

Autonomia pedagógica

Autonomia curricular

Qualidade

Melhoria educativa

\section{RESUMEN:}

As políticas curriculares portuguesas inspiram-se no discurso das políticas internacionais que recomendam às escolas maior autonomia. Em Portugal, implementaram-se, a partir de 2017, medidas em torno da autonomia e flexibilidade curricular. Neste artigo procuramos compreender o quadro jurídico-normativo da Autonomia e Flexibilidade Curricular (AFC), patente nas orientações educativas do Perfil dos Alunos à Saída da Escolaridade Obrigatória, do Currículo dos Ensinos Básicos e Secundário, das Aprendizagens Essenciais, da Estratégia Nacional de Educação para a Cidadania, da Educação Inclusiva e do Programa Nacional de Promoção do Sucesso Escolar. Procedemos a um estudo exploratório, de natureza qualitativa, assente numa abordagem descritiva e interpretativa, centrado num estudo de caso único - a dimensão normativa da AFC em Portugal. Utiliza-se como técnica de recolha de dados a análise documental e como técnicas de análise e tratamento dos dados a análise de conteúdo e a triangulação dos normativos referenciados. Ao nível das intenções declaradas na narrativa da política educativa, preconizam-se medidas inovadoras nos domínios curricular e pedagógico, com vista à melhoria e qualidade do ensino e das aprendizagens, invocando no entender dos autores a necessidade de aprofundar processos substantivos da autonomia das escolas num modelo de administração educacional que em Portugal se mantém centralizado e desconcentrado.

\section{KEYWORDS: \\ Educational policy \\ Pedagogical autonomy \\ Curricular autonomy \\ Quality \\ Educational \\ improvement}

\section{ABSTRACT:}

Portuguese curriculum policies are inspired by the discourse of international policies that recommend schools greater autonomy. In Portugal, since 2017, measures have been implemented around curriculum autonomy and flexibility. In this article, we seek to understand the legal-normative framework of Curricular Autonomy and Flexibility (AFC), evident in the educational guidelines of the Students' Profile by the End of Compulsory Schooling, the Basic and Secondary Education Curriculum, Essential Learning, the National Education Strategy for Citizenship, Inclusive Education and the National Program for the Promotion of School Success. We carried out an exploratory study, of a qualitative nature, based on a descriptive and interpretive approach, centered on a single case study - the normative dimension of AFC in Portugal. Document analysis is used as a data collection technique and as data analysis and treatment techniques, content analysis and the triangulation of referenced standards. In terms of the intentions declared in the educational policy narrative, innovative measures are recommended in the curricular and pedagogical domains, with a view to improving and quality of teaching and learning, invoking in the authors' understanding the need to deepen substantive processes of school autonomy in a educational administration model that in Portugal remains centralized and deconcentrated.

CÓMO CITAR:

Silva, S. y Fraga, N. (2021). Autonomia e flexibilidade curricular como instrumentos gestionários. O caso de Portugal. REICE. Revista Iberoamericana sobre Calidad, Eficacia y Cambio en Educación, 19(2), 37-54. https://doi.org/10.15366/reice2021.19.2.003

${ }^{*}$ Contacto: sofia.silva@staff.uma.pt

ISSN: $1696-4713$

www.rinace.net/reice

revistas.uam.es/reice
Recibido:

1 de septiembre 2020

1a Evaluación: 3 de enero 2021

2a Evaluación: 9 de febrero 2021

Aceptado: 2 de marzo 2021 


\section{A regulação transnacional das políticas de educação}

Entendamos a globalização, segundo a perspetiva de Dale (2004), como "um conjunto de dispositivos político-económicos para a organização da economia global, conduzido pela necessidade de manter o sistema capitalista, mais do que qualquer outro conjunto de valores. A adesão aos seus princípios é veiculada através da pressão económica e da percepção do interesse nacional próprio" (p. 436). Nesta perspetiva, torna-se urgente compreender a globalização, no sentido de interpretar a força do efeito extranacional e de interpretar como é que este processo pode afetar as políticas e as práticas educativas nacionais.

Para este efeito, Dale (2004) reflete sobre duas conceções distintas: a Cultura Educacional Mundial Comum (CEMC) e a Agenda Globalmente Estruturada da Educação (AGEE). A primeira, desenvolvida por John Meyer e seus colegas em Stanford, defende que "o desenvolvimento dos sistemas educativos nacionais e as categorias curriculares se explicam através de modelos universais de educação, de estado e de sociedade, mais do que através de fatores nacionais distintivos" (p. 425), enquanto que a segunda encara "a mudança de natureza da economia capitalista mundial como a força directora da globalização e procuram estabelecer o seus efeitos, ainda que intensamente mediados pelo local, sobre os sistemas educativos" (p. 426).

Atendendo à perspetiva dos autores que defendem a CEMC, as políticas educativas nacionais consistem em meras interpretações de ideologias, culturas e valores de nível mundial, utilizadas com o propósito de legitimar as suas opções governativas.

Assim sendo, o currículo é considerado a conjugação de ideais e convenções educacionais mundiais, ao invés de uma decisão ponderada e contextualizada de sociedades individuais e locais. A definição do conhecimento legítimo para ser ensinado nas escolas, bem como a seleção e a hierarquização desses conhecimentos são, assim, claramente prescritos externamente.

De acordo com a AGEE, a influência da globalização na educação manifesta-se através da proeminência e do papel crucial que as agências multilaterais como a Organização para a Cooperação e Desenvolvimento Económico, a Organização das Nações Unidas para a Educação, a Ciência e a Cultura e o Banco Mundial desempenham. A este respeito, Dale (2004) salienta três questões fundamentais: a quem é ensinado o quê, como, por quem e em que circunstâncias? Como, por quem e através de que estruturas, instituições e processos são definidos estes conhecimentos e de que forma são geridos e organizados? E quais são as consequências individuais e sociais destas estruturas e processos? Estas questões centram-se, por um lado, nos princípios e processos da educação formal e, por outro, na definição, formulação, transmissão e avaliação do conhecimento escolar.

Em termos gerais, estas duas abordagens enfatizam a relevância das forças supranacionais sobre os sistemas educativos nacionais, isto é, o impacto e a influência externa que as políticas educativas nacionais sofrem e que afetam estruturas, estratégias, processos e práticas. Assim sendo, constata-se que os quadros regulatórios nacionais são moldados e delimitados supra e transnacionalmente, bem como por forças político-económicas nacionais, sendo desta forma que a globalização exerce os seus efeitos sobre os sistemas educativos nacionais (Dale, 1998; Fraga, 2020; Teodoro, 2020).

Esta perspetiva é igualmente partilhada por Fernandes (2011) ao asseverar que certas organizações têm desempenhado um papel determinante na afirmação de novos rumos para a educação, quer na Europa, quer no Mundo, e cujas diretrizes emanadas exercem uma forte influência nas políticas educativas nacionais.

Tomemos como exemplo a OCDE, que se define como uma organização intergovernamental, que reúne cerca de 30 dos países mais desenvolvidos do Mundo comprometidos com os princípios de uma economia de mercado e de uma democracia pluralista (OCDE, 1997). Apesar de ser uma organização económica, a OCDE possui uma visão holística dos propósitos múltiplos da educação, pelo que sempre enfatizou o papel que o conhecimento deve desempenhar no desenvolvimento económico e social, relacionando a importância do capital humano e do investimento educacional com a produtividade e a inovação (Rizvi e Lingard, 2012). A OCDE surge então conotada com um novo discurso de globalização e consequentes implicações para as políticas educativas.

Os efeitos da globalização repercutem-se nas estratégias educativas na formulação de políticas para uma economia mundial globalizada, na tentativa de os Estados se tornarem mais competitivos. A definição das políticas educativas estabelece-se, assim, através de uma relação entre o plano internacional e os planos nacionais. Por um lado, e na tentativa de estabelecer uma "racionalidade científica que permitisse formular leis gerais 
capazes de guiar, em cada país, a ação reformadora no campo da educação" (Teodoro, 2001, p. 127), as inúmeras iniciativas (ex: estudos, exames, publicações, seminários e congressos, entre outros) das organizações internacionais desempenham um papel crucial de

normalização das políticas educativas nacionais, estabelecendo uma agenda que fixa não apenas prioridades, mas igualmente as formas como os problemas se colocam e equacionam, e que constituem uma forma de fixação de mandato, mais ou menos explíito conforme a centralidade dos países. (Teodoro, 2012, p. 52)

Por outro lado, as autoridades nacionais procuram incessantemente o trabalho desenvolvido pelas organizações internacionais como meio de legitimação das opções internas assumidas, enquanto que estas últimas atuam em prol do interesse coletivo dos mais poderosos, ou sejam dos "centros metropolitanos dominantes" (Dale, 2004, p. 456).

Parece, pois, consensual que as recomendações das principais organizações internacionais assumem uma enorme pressão e influência na definição das políticas educativas locais, especialmente no caso de países semiperiféricos, como é o caso de Portugal (Fernandes, 2011; Rizvi e Lingard, 2012; Teodoro, 2011, 2012).

Teodoro (2012) afirma que essa influência se determina tendo por base os grandes projetos estatísticos internacionais, dos quais destaca o projeto Indicators of Educational Systems (INES) do Centre for Educational Research and Innovation (CERI) da OCDE. Assim sendo, a seleção dos indicadores constitui a questão fulcral na fixação de uma agenda global para a educação, com um grande impacto nas políticas educativas dos países, cuja expressão pública mais reconhecida é a publicação Education at a Glance, editada anualmente desde 1992.

A OCDE estabeleceu, assim, uma importante base de dados de indicadores nacionais de ensino, que acabam por ter uma influência direta na formulação das políticas de educação adotadas pelos diferentes Estados-membros. Estes indicadores têm evoluído ao longo dos tempos, centrando-se, essencialmente, em quatro temas, que pretendem medir os resultados dos sistemas educativos, a saber: 0 acesso à educação, participação e progresso; o ambiente da aprendizagem e a organização das escolas; os recursos humanos e financeiros investidos em educação; e os resultados das instituições educacionais e o impacto do conhecimento (Teodoro, 2012).

Estamos, pois, perante uma evidente obsessão com os resultados, pela necessidade de responder a uma agenda global baseada na comparação internacional de performances e, sobretudo, na competição dos sistemas educativos dos diferentes países. Constata-se, desta forma, o poder e a influência das organizações internacionais, nomeadamente da OCDE que, segundo Teodoro (2012) é "o principal think tank mundial da globalização hegemónica" (p. 57), tornando-se "a principal fonte internacional de expertise técnica em estatísticas educacionais" (Rizvi e Lingard, 2012, p. 543).

Os grandes inquéritos internacionais, tais como o Trends in International Mathematics and Science Study (TIMSS), o Programa Internacional para Avaliação de Estudantes (PISA), o Progress in International Reading Literacy Study (PIRLS) ou o Teaching and Learning International Survey (TALIS), e a sua permanente metodologia comparativa em relatórios, estudos e recomendações divulgados internacionalmente, tornaram-se uma das principais formas de governação, com o propósito de facultar evidências para as políticas educacionais. Pretende-se que estas estatísticas e indicadores internacionalmente comparáveis sirvam para aumentar a qualidade e a equidade dos sistemas de educação, assentes na convicção de que a educação é primordial na formação de capital humano para que as economias nacionais possam fazer frente à concorrência internacional e às pressões globais. Na verdade, os resultados destes inquéritos internacionais revelam uma capacidade cada vez maior para regulamentar prioridades e linhas de ação em políticas de educação, tanto nos Estados-membros como em outros países.

Para além destes testes à escala internacional, inúmeros têm sido os estudos/publicações divulgados pela OCDE e que têm servido de mote para o desenvolvimento das políticas educativas locais, como é o caso de Portugal, designadamente:

- Global competency for an inclusive world (OCDE, 2016a).

- The future of education and skills: Education 2030 (OCDE, 2016b).

- Education at a glance (OCDE, 2018a). 
- Curriculum flexibility and autonomy in Portugal. An OECD review (OCDE, 2018b).

- Preparing ouryouth for an inclusive and sustainable world. The OECD PISA global competence framework (OCDE, 2018c).

- Trends shaping education (OCDE, 2019).

Numa era caracterizada por um processo de globalização exponencial, de novos conhecimentos científicos e um rápido desenvolvimento tecnológico, o mundo atual enfrenta desafios sem precedentes de caráter social, económico e ambiental complexos. Simultaneamente, deparamo-nos com uma panóplia de novos desafios e oportunidades para o desenvolvimento humano, perante os quais a educação pode, efetivamente, contribuir para fazer a diferença.

A este respeito, a OCDE (2016b) relembra que estamos perante um mundo cada vez mais volátil, incerto, complexo e ambíguo, pelo que é urgente preparar as crianças - que estão a entrar agora no sistema educativo e que serão jovens adultos em 2030 - para empregos que ainda não foram criados, para tecnologias que ainda não foram inventadas e para resolver problemas que ainda não foram antecipados.

Neste âmbito, os alunos têm de desenvolver a curiosidade, a imaginação, a resiliência e a autorregulação, no sentido de respeitar as ideias, perspetivas e valores dos outros e de aprender a lidar com o fracasso e a rejeição perante as eventuais adversidades. Mais do que conseguir um bom emprego, as pessoas também precisam preocupar-se com o bem-estar dos indivíduos, das suas comunidades e do planeta (OCDE, 2016a, 2016b). Neste contexto, a OCDE (2016b) lançou The future of education and skills: Education 2030, com o propósito de orientar os países a encontrar respostas para duas questões essenciais:

- Quais os conhecimentos, habilidades, atitudes e valores que os alunos precisam para prosperar no mundo atual?

- Como é que os sistemas educativos podem desenvolver esses conhecimentos, habilidades, atitudes e valores de forma eficaz?

A OCDE desenvolveu um quadro de aprendizagens (Figura 1) que demonstra que, para além de se reconhecer a individualidade dos alunos, importa também identificar o conjunto mais amplo de relações que se estabelecem com professores, colegas, famílias e comunidades e que influenciam o seu processo de aprendizagem.

Figura 1

Quadro de aprendizagem OCDE 2030

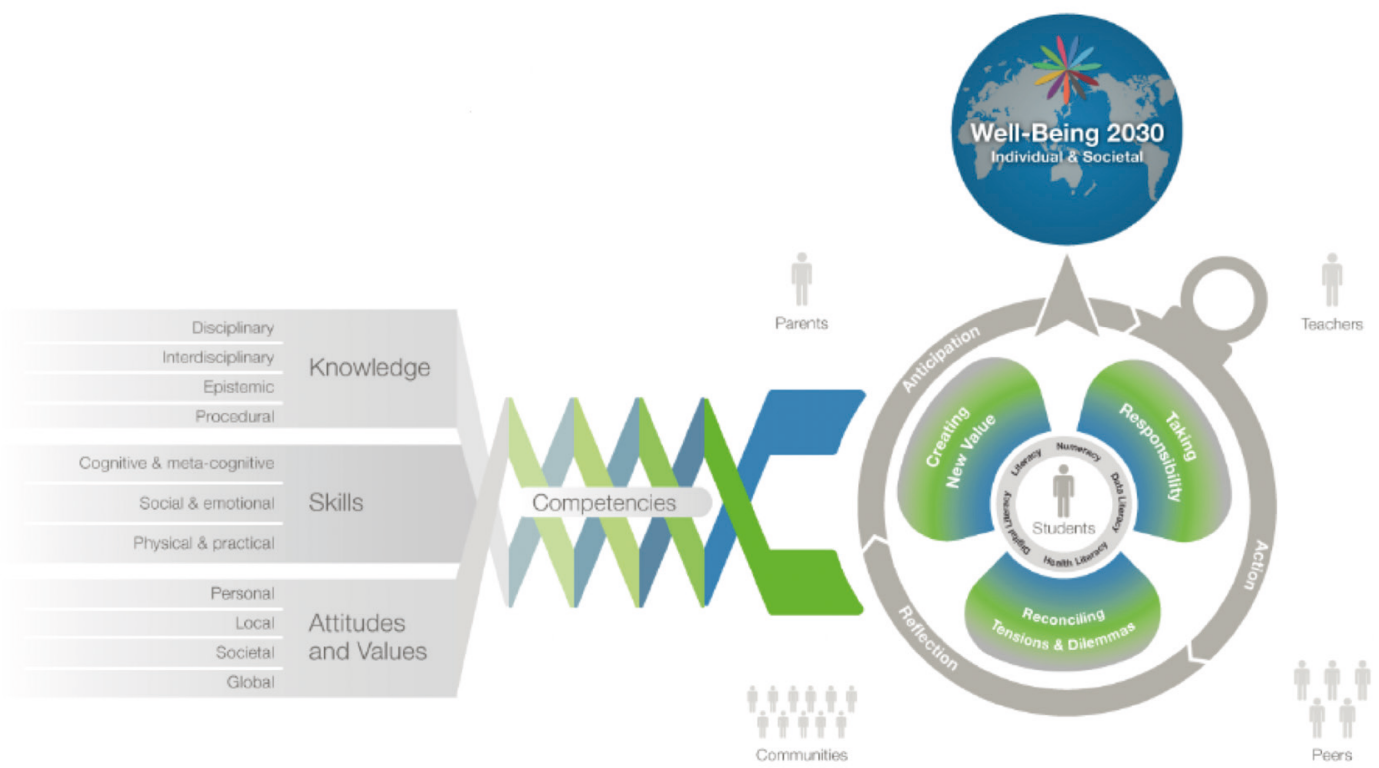

Nota. Recuperado de OCDE (2016b, p. 4). 
Este quadro de aprendizagens assenta no conceito de "competência global", que é descrito como “(...) a multidimensional capacity. Globally competent individuals can examine local, global and intercultural issues, understand and appreciate different perspectives and world views, interact successfully and respectfully with others, and take responsible action toward sustainability and collective well-being" (OCDE, 2016b, p. 4).

Relembremos a noção de competência, proposta por Perrenoud (1999), que a define como algo que "permite afrontar e regular adequadamente uma família de tarefas e de situações, apelando para noções, conhecimentos, informações, procedimentos, métodos, técnicas ou ainda a outras competências, mais específicas". O autor refere ainda que "possuir conhecimentos ou capacidades não significa ser competente”. (p. 2). Neste sentido, compete à escola a função de desenvolver competências, isto é, de relacionar os saberes e operacionalizá-los em situações complexas. O conceito de competência neste contexto implica mais do que apenas a mera aquisição de conhecimentos e habilidades, envolve a mobilização e contextualização destes conhecimentos, habilidades na resolução de problemas e na tomada de decisões. Assim sendo, os alunos necessitam de conhecimento técnico especializado, no entanto, os saberes disciplinares promovidos pela escola continuam a ser importantes, enquanto matéria-prima a partir da qual o novo conhecimento é desenvolvido (OCDE, 2018c).

No Mundo atual, os alunos têm de aplicar os seus conhecimentos em circunstâncias desconhecidas e em constante evolução. Para este efeito, necessitam de habilidades cognitivas e metacognitivas (ex: pensamento crítico, pensamento criativo, aprender a aprender e autorregulação), habilidades socioemocionais (empatia, autoeficácia e colaboração) e habilidades técnicas e tecnológicas (ex: usar dispositivos de tecnologia da informação e comunicação). O uso desses conhecimentos e habilidades, por sua vez, deve ser mediado por atitudes e valores (ex: motivação, confiança e respeito pela diversidade). Salientamos que tais construções pedagógicas e curriculares não se podem desenvolver à margem da justiça, em particular de uma cultura de escola para a justiça social, de um compromisso de toda a comunidade relativamente à aprendizagem e aos seus processos, bem como a partir de processos justos de ensino-aprendizagem (Murillo e Krichesky, 2015).

A OCDE tem defendido também que atualmente as sociedades requerem trabalhadores preparados para empregos altamente qualificados, que possuam competências na utilização das tecnologias de informação e comunicação e que demonstrem atitudes favoráveis à mudança e à inovação. Neste sentido, os trabalhadores devem possuir determinadas competências, tais como a adaptabilidade, a organização, a responsabilidade, a integridade, a flexibilidade, habilidades comunicacionais, a criatividade, a resolução de problemas, a capacidade de tomada de decisões, a capacidade de trabalhar com autonomia e sob pressão, a autonomia, a proatividade, o empreendedorismo, a liderança e o trabalho em equipa (Rizvi e Lingard, 2012).

Face ao exposto é percetível que a linha que separa os cenários nacionais e internacionais de construção da política educativa é ténue e tende à assunção de políticas híbridas de educação, e que, segundo Lima e Sá (2017) oferecem um "pacote de soluções padronizadas” (p. 8) para os problemas que afetam os sistemas educativos dos diferentes países.

Esta agenda caracteriza-se por ser simultaneamente global e local, pois orienta os sistemas educativos dos diversos países a atender à conjuntura transnacional em que estão inseridos, num mundo cada vez mais globalizado e competitivo (Fernandes, 2011), mas também exige que não se descure a realidade local e as suas especificidades sociais e culturais. Esta questão tem originado inúmeros desafios para os diversos países, cujas políticas e reformas educativas têm oscilado ora entre um cariz mais centralizado, na tentativa de balizar e fazer aplicar estas diretrizes, ora descentralizado, dotando de autonomia e espaços de decisão os atores locais (Fernandes, 2011). É em este titubear que Portugal tem vindo a construir o seu quadro jurídico-normativo em termos de política educativa.

\section{Opções metodológicas}

Este estudo exploratório assume-se de natureza qualitativa, assente numa abordagem descritiva e interpretativa, centrado em um estudo de caso único (Afonso, 2005; Bryman, 1988; Carmo e Ferreira, 1998; Flick, 2009; Fortin, 2009; Lessard-Hébert et al., 2008; Merriam, 1998; Pardal e Lopes, 2011; 
Sousa, 2005; Stake, 2007; Tuckman, 2000; Yin, 2005), a dimensão normativa da Autonomia e Flexibilidade Curricular em Portugal.

Numa abordagem sistémica, o estudo de caso é realizado com um dos propósitos básicos: explorar, descrever e explicar um fenómeno, tendo como objetivo compreender o caso no seu todo e na sua unicidade, ou seja, trata-se de "estudar o que é particular, único e específico" (Afonso, 2005, p. 70), procurando descobrir o que há nele "de mais essencial e característico" e contribuir para a "compreensão global de um fenómeno de interesse" (Oliveira e Ferreira, 2014, p. 96). Neste âmbito, pretende-se compreender os princípios pedagógicos e curriculares do discurso jurídico-normativo em Portugal, com especial ênfase na descrição e na interpretação deste processo.

De forma a concretizar o objetivo do estudo, utiliza-se como técnica de recolha de dados a análise documental e como técnicas de análise e tratamento dos dados a análise de conteúdo e a triangulação do discurso jurídico-normativo patente no Perfil dos Alunos à Saída da Escolaridade Obrigatória, no Currículo dos Ensinos Básicos e Secundário, nas Aprendizagens Essenciais, na Estratégia Nacional de Educação para a Cidadania, na Educação Inclusiva e no Programa Nacional de Promoção do Sucesso Escolar.

\section{A realidade curricular da escola pública em Portugal}

Numa era marcada pela aceleração vertiginosa da mudança a todos os níveis, a que Lyotard (1989) designou de "pós-modernidade" e Bauman $(2001,2007)$ de "modernidade líquida", o mundo atual enfrenta desafios de caráter social, económico e ambiental. Estamos perante um mundo rápido e "complexo", pautado pela "desordem" e pela "certeza da incerteza" (Morin, 1996; 2002), associado a um processo de globalização exponencial e um desenvolvimento científico e tecnológico sem precedentes.

Atendendo à conjuntura atual e aos pressupostos da era "pós-moderna" (Lipovetsky e Charles, 2018), e por força das profundas mudanças e do intenso fenómeno globalizador, são colocadas novas exigências educativas à escola, que se repercutem, essencialmente, no terreno curricular e pedagógico (Moreira e Pacheco, 2006). Perante este cenário, torna-se preponderante refletir até que ponto as organizações educativas têm acompanhado este desenvolvimento e se o currículo oficial se mantém adequado na atualidade. Na verdade, as reorganizações curriculares em Portugal têm sido fortemente influenciadas pelas políticas curriculares internacionais do final do século XX, que colocaram o currículo no centro do debate político.

Entendamos o currículo como o corpo de aprendizagens que socialmente se reconhecem como necessários num dado tempo e contexto (Roldão, 2009). Mas não esqueçamos que o currículo é uma construção intencional e racional (Sousa e Fino, 2014), bem como uma construção social (Goodson, 2001), ou seja, "um artefacto social" concebido para realizar determinados objetivos específicos (Goodson, 1997, p. 17), pelo que não é, de forma alguma, neutro (Apple, 2006). Assim sendo, o currículo constitui o núcleo da existência da escola, que advém do reconhecimento social da necessidade de transmitir um conjunto de saberes de forma sistemática a um grupo ou sector da sociedade (Roldão e Almeida, 2018).

Em Portugal, com a massificação do ensino e posterior alargamento da escolaridade obrigatória até aos 18 anos, em 2009, generalizou-se o acesso à educação, pelo que o foco passou então a ser o sucesso dos alunos, ou seja, exige-se às escolas que sejam mais eficazes em termos da qualidade das aprendizagens. A eficácia das escolas traduz-se, desta feita, no sucesso educativo de todos os alunos, numa perspetiva inclusiva e de equidade, até porque "não é o contacto com a informação que garante, por si só, a aprendizagem a quem quer que seja", sobretudo se os alunos não apresentarem qualquer familiaridade com o assunto a estudar (Cosme, 2018, p. 10). Os principais desafios para o sistema educativo português são a promoção do sucesso, a educação para a cidadania e a inclusão (Costa, 2019). 
Neste sentido, é imperativo uma reflexão profunda sobre que conhecimentos, capacidades, atitudes e valores os alunos devem possuir no século XXI e em que medida o sistema educativo português os tem desenvolvido (OCDE, 2018a).

\subsection{Perfil dos alunos à saída da escolaridade obrigatória}

O Ministério da Educação português criou um documento de referência - o Perfil dos Alunos à Saída da Escolaridade Obrigatória, adiante designado por Perfil dos Alunos, aprovado pelo Despacho $\mathrm{n}^{\circ}$ $6478 / 2017$, de 26 de julho, que estabelece a matriz a que deve obedecer o desenvolvimento do currículo. Este documento, que é "fruto de um amplo debate que envolveu múltiplos setores da sociedade e um trabalho de comparabilidade internacional" (Costa, 2019, p. 16), constitui-se como um referencial para todas as decisões de cariz educativo e uma orientação comum para as escolas e as ofertas educativas que proporcionam, no âmbito da escolaridade obrigatória, no que diz respeito ao desenvolvimento curricular, planeamento e avaliação interna e externa das aprendizagens.

Figura 2

Perfil dos Alunos à Saída da Escolaridade Obrigatória

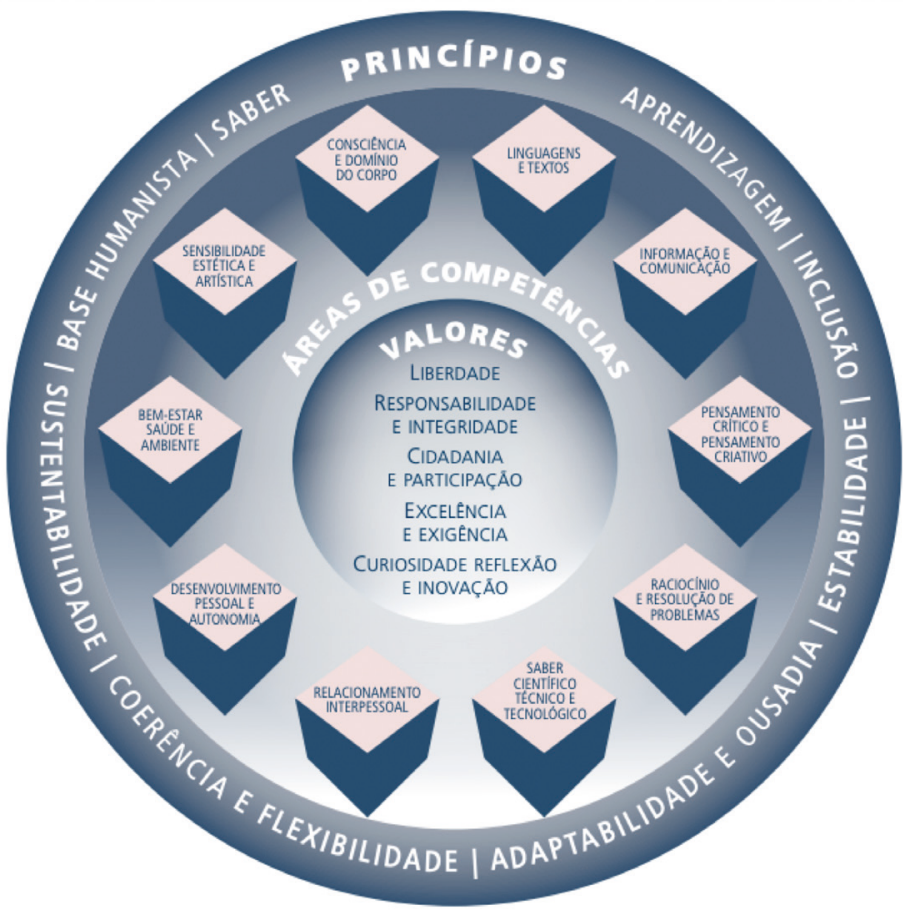

Nota. Recuperado de Ministério da Educação (2017, p. 12).

O Perfil dos Alunos (Figura 2) apresenta-se estruturado em princípios, visão, valores e áreas de competências a desenvolver até ao fim da escolaridade obrigatória.

Os oito princípios fundamentam todas as ações relacionadas com a execução e a gestão do currículo na escola, a saber: base humanista, saber, aprendizagem, inclusão, coerência e flexibilidade, adaptabilidade e ousadia, sustentabilidade e estabilidade. A visão de aluno elucida qual o tipo de cidadão que é pretendido para os jovens à saída da escolaridade obrigatória, que consiste na qualificação individual e no exercício de uma cidadania democrática. Os valores, por sua vez, são entendidos como orientações que se exprimem através de comportamentos, atitudes e condutas, nomeadamente a responsabilidade e integridade; a excelência e exigência; a curiosidade, a reflexão e inovação; a cidadania e participação; e a liberdade. As áreas de competências agregam conhecimentos, capacidades e atitudes de natureza diversa (Figura 3), tais como cognitiva e metacognitiva, social e emocional, física e prática. 
Figura 3

Esquema concetual de competências

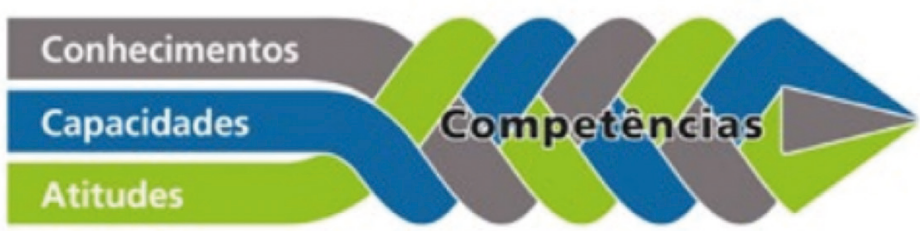

Nota. Recuperado de Ministério da Educação (2017, p. 19).

As dez áreas de competências definidas no Perfil dos Alunos são: (i) linguagens e textos; (ii) informação e comunicação; (iii) pensamento crítico e pensamento criativo; (iv) raciocínio e resolução de problemas; (v) saber científico, técnico e tecnológico; (vi) relacionamento interpessoal; (vii) desenvolvimento pessoal e autonomia; (viii) bem-estar, saúde e ambiente; (ix) sensibilidade estética e artística; e (x) consciência e domínio do corpo.

Este Perfil dos Alunos visa dotar os estudantes, no final dos 12 anos de escolaridade obrigatória, de ferramentas cognitivas, emocionais e sociais que lhes permitam prosseguir os estudos ou integrar, de imediato, o mercado de trabalho. Nas palavras de Costa (2019), espera-se que o aluno não seja "apenas detentor de saber científico, técnico e tecnológico, mas que vá para além do conhecimento enciclopédico, gerindo informação, pensando criticamente, capaz de raciocinar e resolver problemas, capaz de se relacionar com a $\operatorname{arte}^{\prime}$ (p. 16).

\subsection{Projeto de Autonomia e Flexibilidade Curricular (PAFC)}

Em consonância com o Perfil dos Alunos, e com o propósito de melhorar a qualidade das aprendizagens e promover a equidade na prestação do serviço educativo, foi criado em 2017, através do Despacho $\mathrm{n}^{\circ}$ 5908/2017, de 5 de julho, um projeto piloto, em regime de experiência pedagógica, designado Autonomia e Flexibilidade Curricular, para o ano escolar 2017/2018. Tendo como destinatários as turmas de anos iniciais de ciclo $\left(1^{\circ}, 5^{\circ}\right.$ e $7^{\circ}$ anos de escolaridade), do $10^{\circ}$ ano de escolaridade e do $1^{\circ}$ ano de formação de cursos organizados em ciclos de formação, o PAFC abrangeu 223 agrupamentos escolares e escolas não agrupadas da rede pública e privada (tabela 1), que voluntariamente aderiram à sua implementação.

Quadro 1

Número de unidades orgânicas envolvidas no PAFC, por Região

\begin{tabular}{lc}
\hline \multicolumn{1}{c}{ Região } & No de unidades orgânicas $^{\circ}$ \\
\hline Norte & 64 \\
Centro & 36 \\
Lisboa e Vale do Tejo & 83 \\
Alentejo & 12 \\
Algarve & 10 \\
Região Autónoma dos Açores & 5 \\
Região Autónoma da Madeira & 10 \\
Escolas Portuguesas no Estrangeiro & 3 \\
Total & 223 \\
\hline
\end{tabular}

Nota. Recuperado de DGE (2018, p. 2).

No total, integraram este projeto 2278 turmas do ensino básico e secundário, num total de 46910 alunos e 6832 professores envolvidos (Quadro 2). 
Quadro 2

Número de turmas, por ano e modalidade de ensino, alunos e professores envolvidos no PAFC

\begin{tabular}{|c|c|c|c|c|c|c|c|c|c|c|}
\hline \multirow[b]{3}{*}{ Anos } & \multicolumn{6}{|c|}{ Ensino Básico } & \multicolumn{4}{|c|}{ Ensino Secundário } \\
\hline & \multicolumn{3}{|c|}{ Geral } & \multicolumn{2}{|c|}{$\mathrm{CAE}^{1}$} & \multirow{2}{*}{$\frac{\mathrm{CEF}^{2}}{\text { Tipo } 2}$} & \multirow{2}{*}{$\frac{\mathrm{CCH}^{3}}{10^{\circ}}$} & \multirow{2}{*}{$\frac{\text { CAE }}{10^{\circ}}$} & \multirow{2}{*}{$\frac{\mathrm{CP}^{4}}{1^{\mathrm{o}}}$} & \multirow{2}{*}{ Total } \\
\hline & $1^{\circ}$ & $5^{\mathrm{o}}$ & $7^{\circ}$ & $5^{\mathrm{o}}$ & $7^{\circ}$ & & & & & \\
\hline Turmas & 743 & 623 & 591 & 24 & 24 & 15 & 157 & 3 & 96 & 2278 \\
\hline Alunos & 14129 & 13008 & 12606 & 458 & 288 & 225 & 3804 & 73 & 2319 & 46910 \\
\hline Professores & 6832 & & & & & & & & & \\
\hline
\end{tabular}

Nota. ${ }^{1}$ Cursos artísticos especializados. ${ }^{2}$ Cursos de educação e formação ${ }^{3}$ Cursos científico-humanísticos. ${ }^{4}$ Cursos profissionais. Recuperado de DGE (2018, p. 3).

O acompanhamento e monitorização do PAFC foi segurado por equipas centrais (coordenadora e técnica), bem como por equipas regionais, constituídas por elementos dos diversos organismos do Ministério da Educação. Para além destas, foi ainda constituído um conselho consultivo, composto por personalidades de reconhecido mérito na área da educação.

\subsection{Enquadramento jurídico-normativo}

Esta experiência pedagógica deu origem, um ano mais tarde, ao Decreto-Lei $n^{0} 55 / 2018$, de 6 de julho, que confere às escolas a possibilidade de "gerir o currículo dos ensinos básico e secundário, partindo das matrizes curriculares-base, assente na possibilidade de enriquecimento do currículo com os conhecimentos, capacidades e atitudes que contribuam para alcançar as competências previstas no Perfil dos Alunos (...)" $\left(\right.$ artigo $\left.3^{\circ}\right)$. Com esta medida política pretende-se que,

o currículo seja equacionado como um instrumento que as escolas podem gerir e desenvolver localmente de modo que todos os alunos alcancem as competências previstas no Perfil dos Alunos à Saída da Escolaridade Obrigatória. Para tal, considera-se fundamental que as principais decisões a nivel curricular e pedagógico sejam tomadas pelas escolas e pelos professores. (Preâmbulo do Decreto-Lei n ${ }^{\circ} 55 / 2018$ )

É então conferida à escola a possibilidade de participar no desenvolvimento curricular até ao limite de $25 \%$ da carga horária semanal (no caso das matrizes com organização semanal) e da carga horária total das componentes sociocultural e científica previstas para o ciclo de formação (artigo $12^{\circ}$, ponto 1), bem como de encontrar as opções curriculares mais adequadas ao Projeto Educativo de Escola, aos contextos específicos e às necessidades dos seus alunos. Pode ainda ser conferida às escolas uma gestão superior a $25 \%$ das matrizes curriculares-base, para o "desenvolvimento de planos de inovação curricular, pedagógica ou de outros domínios” (artigo $12^{\circ}$, ponto 3 ).

Em 2018 deu-se mais um passo rumo à designada gestão flexível do currículo, que havia sido consagrada nos Decretos-Lei $n^{\circ} 6$ e 7/2001, de 18 de janeiro, que definiram a reorganização curricular dos ensinos básicos e secundário, respetivamente. Já em 2001 se reconhecia a necessidade de ultrapassar uma visão de currículo como "um conjunto de normas a cumprir de modo supostamente uniforme em todas as salas de aula" (Preâmbulo do Decreto-Lei $n^{\circ}$ 6/2001) e de apoiar o desenvolvimento de novas práticas de gestão curricular, no âmbito da crescente autonomia das escolas. Com a publicação destes diplomas, assumia-se claramente que as escolas portuguesas

têm vindo a construir processos de gestão curricular no quadro de uma flexibilidade que procura encontrar respostas adequadas aos alunos e aos contextos concretos em que os professores trabalham diariamente [pelo que se torna fundamental atribuir às escolas] uma maior capacidade de decisão relativamente ao desenvolvimento e gestão das diversas componentes do currículo e a uma maior articulação entre elas, bem como um acréscimo de responsabilidade na organização das ofertas educativas. (Preâmbulo do Decreto-Lei n ${ }^{\circ} 6 / 2001$ )

Neste sentido, estabelece-se que o desenvolvimento do currículo nacional deve ser adequado aos contextos locais, sob a forma de um Projeto Curricular de Escola, aprovado pelos órgãos de administração e 
gestão das escolas, e por Projetos Curriculares de Turma, elaborados de acordo com as especificidades e exigências de cada turma.

No entanto, apesar do pioneirismo destes normativos, a partir de 2001, o tema da flexibilidade curricular deixou de estar no centro do debate educativo, uma vez que “(...) através de pequenas mudanças e sobretudo por falta de apoio explícito, ela foi de facto esquecida por tal forma que definhou e morreu sem se dar por isso" (Varela de Freitas, 2019, p. 41).

Em 2012, foi publicado o Decreto-Lei ${ }^{0}$ 139/2012, de 5 de julho, que reorganiza os currículos dos ensinos básico e secundário, retomando o conceito conservador de currículo como "o conjunto de conteúdos e objetivos que, devidamente articulados, constituem a base da organização do ensino e da avaliação do desempenho dos alunos, assim como outros princípios orientadores que venham a ser aprovados com o mesmo objetivo" (artigo $2^{\circ}$ do Decreto-Lei n $\left.{ }^{\circ} 139 / 2012\right)$.

Com a publicação do Decreto-Lei 55/2018, Varela de Freitas (2019, p. 43) considera que "foi aberta uma segunda janela de oportunidade para que a flexibilidade curricular, que em 2001 eu considerava que poderia ser o meio que alterasse significativamente o panorama educativo nacional". Estamos perante "dois grandes níveis de decisão curricular": o "nível central que estabelece o core curriculum", e "o nível de decisão contextual", que permite às escolas, no âmbito da sua autonomia, a "operacionalização e a gestão contextualizada do currículo" (Pacheco et al., 2018, p. 97). Ao nível do discurso normativo, é finalmente reconhecida às escolas a autonomia de romper com o caráter único do currículo prescrito nacionalmente, metaforicamente designado por Formosinho (2007) de "currículo uniforme pronto-a-vestir de tamanho único”.

$\mathrm{Na}$ "concretização de um exercício efetivo de autonomia curricular" é dada a possibilidade às escolas de identificar "opções curriculares eficazes, adequadas ao contexto, enquadradas no projeto educativo e noutros instrumentos estruturantes da escola" (artigo $4^{\circ}$, ponto 1, alínea b, do Decreto-Lei 55/2018).

Roldão (2003a; 2003b) e Roldão e Almeida (2018) designam esta dualidade - a existência de um tronco curricular comum, designado de currículo nacional, versus a autonomia curricular das escolas para decisões curriculares contextualizadas, através dos Projetos Curriculares de Escola e Projetos Curriculares de Turma, em articulação com o emanado no Projeto Educativo de Escola - de "binómio curricular" (Figura 4).

\section{Figura 4}

Articulação entre níveis de decisão curricular

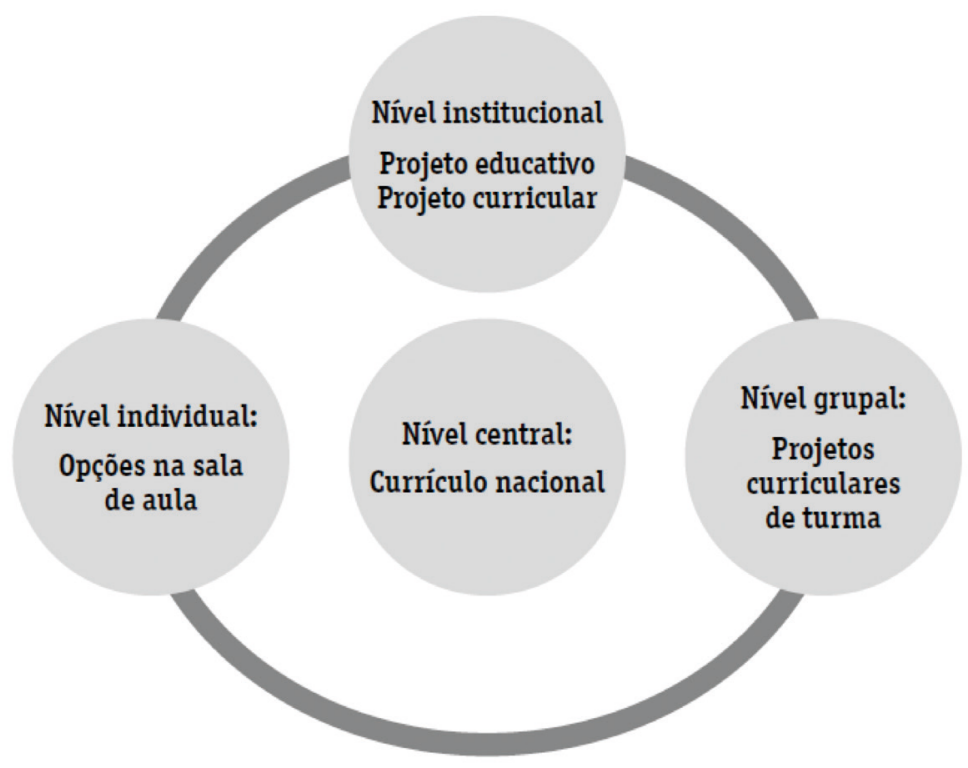

Nota: Recuperado de Roldão e Almeida (2018, p. 20). 
A este respeito, Leite (2006) defende o conceito de "escola curricularmente inteligente", ou seja, é reconhecida à escola a capacidade de tomar decisões curriculares e aos professores competências no processo de construção da aprendizagem dos alunos, deixando estes de ser encarados apenas como meros executores do currículo, mas detentores de autonomia pedagógica e curricular para recontextualizar localmente o currículo.

O currículo é, portanto, assumido como um instrumento que tem como principal propósito "garantir que todos os alunos, independentemente da oferta educativa e formativa que frequentam, alcancem as competências definidas no Perfil dos Alunos à Saída da Escolaridade Obrigatória" (artigo $6^{\circ}$ do Decreto-Lei ${ }^{\circ}$ $55 / 2018$, de 6 de julho).

De forma a cumprir o desiderato de que o currículo esteja ao acesso de todos os alunos, o Decreto-Lei ${ }^{\circ}$ 55/2018 é acompanhado pelo Decreto-Lei ${ }^{0}$ 54/2018, de 6 de julho, alterado pela Lei ${ }^{\circ} 116 / 2019$, de 13 de setembro, que estabelece o regime jurídico da educação inclusiva e apresenta uma mudança de paradigma na abordagem à inclusão, através da aposta

(...) numa escola inclusiva onde todos e cada um dos alunos, independentemente da sua situação pessoal e social, encontram respostas que thes possibilitam a aquisição de um nivel de educação e formação facilitadoras da sua plena inclusão social. (...) [n] uma educação inclusiva que responda às suas potencialidades, expectativas e necessidades no âmbito de um projeto educativo comum e plural que proporcione a todos a participação e o sentido de pertença em efetivas condições de equidade, contribuindo assim, decisivamente, para maiores níveis de coesão social. (Preâmbulo do Decreto-Lei n ${ }^{\circ} 54 / 2018$ )

Costa (2019) assume a inclusão como uma questão curricular e a flexibilidade como um instrumento capaz de conseguir proporcionar a aprendizagem de todos os que não aprendem ou não têm vontade de aprender segundo os standards pré-estabelecidos.

Perante, por um lado, este cenário de educação inclusiva e, por outro, o "binómio curricular" (Roldão, 2003a; 2003b; Roldão e Almeida, 2018), bem como a extensão dos documentos curriculares, que "não libertavam tempo para a inclusão, para a diferenciação pedagógica, para a interdisciplinaridade, constituindo-se como obstáculo a aprendizagens significativas" (Costa, 2019, p. 20), houve a necessidade de definir as aprendizagens essenciais que devem constar no "core curriculum" (Roldão e Almeida, 2018; Skilbeck, 1994, cit. por Pacheco et al., 2018), identificando-se, disciplina a disciplina e ano a ano, o

(...) conjunto comum de conhecimentos a adquirir, identificados como os conteúdos de conhecimento disciplinar estruturado, indispensáveis, articulados conceptualmente, relevantes e significativos, bem como de capacidades e atitudes a desenvolver obrigatoriamente por todos os alunos em cada área disciplinar ou disciplina, tendo, em regra, por referência o ano de escolaridade ou de formação. (artigo $3^{\circ}$, alínea b)

(...) constituem orientação curricular de base, para efeitos de planificação, realização e avaliação do ensino e da aprendizagem (...) (artigo $17^{\circ}$ do Decreto-Lei n ${ }^{o} 55 / 2018$, de 6 de julho)

As aprendizagens essenciais resultam de uma parceria entre as Associações de Professores e a Direção- Geral da Educação, no sentido de identificar o currículo essencial para cada uma das disciplinas/áreas disciplinares que compõem as matrizes curriculares dos diferentes anos de escolaridade, na tentativa de reduzir conteúdos e de estabelecer relações entre as aprendizagens curriculares e o Perfil dos Alunos (Costa, 2019). As aprendizagens essenciais para o ensino básico foram definidas pelo Despacho $\mathrm{n}^{\mathrm{O}}$ 6944$\mathrm{A} / 2018$, de 19 de julho e as aprendizagens essenciais para o ensino secundário pelo Despacho $\mathrm{n}^{\mathrm{o}} 8476$ A/2018, de 31 de agosto.

Estas aprendizagens são "o denominador curricular comum para todos os alunos" (Roldão e Almeida, 2018, p. 44), mas não se restringem apenas ao que o professor ensina, ao invés, pressupõe que as escolas possuam uma maior flexibilidade na gestão dos currículos. Estas aprendizagens assumem especial importância, ao proporcionar espaço curricular para aprofundar temas e desenvolver projetos interdisciplinares, promover um trabalho articulado com outro tipo de aprendizagens, bem como permitir mobilizar componentes regionais/locais do currículo (Cohen e Fradique, 2018). 
Atendendo às áreas de competências consignadas no Perfil dos Alunos, a escola, no contexto da sua comunidade educativa, estabelece opções curriculares estruturantes, que devem estar inscritas no Projeto Educativo, definindo prioridades que visam:

A valorização das artes, das ciências, do desporto, das humanidades, das tecnologias de informação e comunicação, e do trabalho prático e experimental, bem como a integração das componentes de natureza regional e da comunidade local;

A aquisição e desenvolvimento de competências de pesquisa, avaliação, reflexão, mobilização crítica e autónoma de informação, com vista à resolução de problemas e ao reforço da autoestima dos alunos;

A promoção de experiências de comunicação e expressão em língua portuguesa e em línguas estrangeiras nas modalidades oral, escrita, visual e multimodal;

O exercício da cidadania ativa, de participação social, em contextos de partilha e de colaboração e de confronto de ideias sobre matérias da atualidade;

A implementação do trabalho de projeto como dinâmica centrada no papel dos alunos enquanto autores, proporcionando aprendizagens significativas. (artigo $19^{\circ}$ do Decreto-Lei $\mathrm{n}^{\circ} 55 / 2018$, de 6 de julho)

O planeamento curricular, por sua vez, é suportado pelo conhecimento específico do meio em que a escola se insere, "tendo como finalidade a adequação e contextualização do currículo ao projeto educativo da escola e às características dos alunos” (artigo 18 ${ }^{\circ}$, ponto 1). As opções estruturantes de natureza curricular, nomeadamente os critérios de organização e de gestão pedagógica, devem estar consagradas no Projeto Educativo de Escola, bem como noutros instrumentos de planeamento curricular, nomeadamente os Planos Curriculares de Turma, entre outros, sendo que estes devem ser dinâmicos e traduzir uma visão interdisciplinar do currículo (artigo $20^{\circ}$ do Decreto-Lei $n^{\circ} 55 / 2018$, de 6 de julho).

O Projeto Educativo de Escola é, como já referimos, o documento que consagra a orientação educativa dos estabelecimentos de educação e ensino. Sendo assim, o Projeto Educativo constitui-se como referência no trabalho de planeamento, realização e avaliação do processo de ensino-aprendizagem, a concretizar ao nível da turma ou do ano de escolaridade.

O instrumento de planeamento curricular de cada turma previsto é o Plano Curricular de Turma, no qual se define o percurso pedagógico da turma, atendendo às suas especificidades e que deve assentar numa visão interdisciplinar do currículo, tendo como referencial o currículo nacional, as aprendizagens essenciais e o Perfil dos Alunos à Saída da Escolaridade Obrigatória.

Neste sentido, as escolas podem gerir $25 \%$ da carga horária semanal inscrita nas matrizes curriculares-base, por ano de escolaridade. As matrizes curriculares-base são definidas como

o conjunto de componentes de currículo, áreas disciplinares e disciplinas, que integram os planos curriculares de âmbito nacional, por ciclo e ano de escolaridade ou por ciclo de formação, bem como a carga horária prevista para cada um deles, que serve de suporte ao desenvolvimento do currículo concretizado nos instrumentos de planeamento curricular, ao nível da escola e da turma ou grupo de alunos. (artigo $3^{\circ}$ do Decreto-Lei $\mathrm{n}^{\circ}$ 55/2018, de 6 de julho)

Isto significa, portanto, que as escolas possuem autonomia e podem optar por criar domínios de autonomia curricular, novas disciplinas na oferta complementar, outras formas de gestão do tempo e dos espaços, trabalho de projeto e variantes locais do currículo (artigo $19^{\circ}$, ponto 2 ). Contudo, é imperativo a salvaguarda da "existência das áreas disciplinares e disciplinas previstas nas matrizes curriculares-base" (artigo $6^{\circ}$, ponto 2, do Decreto-Lei $n^{\circ} 55 / 2018$ ), o que denota, já em si, o cariz centralizante destas medidas.

No caso da Região Autónoma da Madeira (RAM), e no intuito de reforçar a autonomia pedagógica e organizacional conquistada pelos estabelecimentos de educação e ensino da RAM, foi publicado o Decreto Legislativo Regional $n^{0}$ 11/2020/M, de 29 de julho (no qual foram adaptados os regimes constantes do 
Decreto-Lei $n^{0} 54 / 2018$, de 6 de julho, alterado pela Lei $n^{0} 116 / 2019$, de 13 de setembro, e do Decreto-Lei $\mathrm{n}^{\mathrm{o}} 55 / 2018$, de 6 de julho).

Esta adaptação surge com o propósito de integrar "o que, a nível nacional, é considerado importante e imprescindível para todos", mas simultaneamente adequar os conhecimentos e as competências dos alunos às realidades, vivências e necessidades dos contextos regional e local. Pretende-se, desta forma, valorizar a identidade e a cultura regional, bem como estimular as potencialidades de cada comunidade local, numa Região que "assume intencionalmente a diversidade e a contextualização como referentes de todo o trabalho educativo", promovendo o envolvimento ativo dos alunos, famílias e restante comunidade (Preâmbulo do Decreto Legislativo Regional n 11/2020/M, de 29 de julho).

A Estratégia Nacional de Educação para a Cidadania (ENEC) constitui, igualmente, um documento de referência, em articulação com o Perfil dos Alunos, com as Aprendizagens Essenciais e com a reintrodução da componente de Cidadania e Desenvolvimento no currículo, prevista no Decreto-Lei $n^{\circ} 55 / 2018$, que era até então opcional. Esta estratégia foi apresentada ao Governo em janeiro de 2017, pelo Grupo de Trabalho de Educação para a Cidadania, criado pelo Despacho nº 6173/2016, de 10 de maio.

Este documento enuncia as áreas a trabalhar na formação dos cidadãos, reforçando o papel da cidadania na educação e

integra um conjunto de direitos e deveres que devem estar presentes na formação cidadã das crianças e dos jovens portugueses, para que no futuro sejam adultos e adultas com uma conduta cívica que privilegie a igualdade nas relações interpessoais, a integração da diferença, o respeito pelos Direitos Humanos e a valorização de conceitos e valores de cidadania democrática, no quadro do sistema educativo, da autonomia das escolas e dos documentos curriculares em vigor. (Governo da República Portuguesa, 2017, p. 2)

Partindo do pressuposto de que temas como os direitos humanos, a igualdade de género, a sustentabilidade, a educação ambiental e a literacia financeira, entre outros, devem ser trabalhadas pela escola, estas possuem plena liberdade para organizar esta área curricular, integrando com outras áreas do currículo (Costa, 2019).

Foi igualmente criado o Programa Nacional de Promoção do Sucesso Escolar (PNPSE) - Resolução do Conselho de Ministros $n^{0}$ 23/2016, de 11 de abril - num quadro de valorização da igualdade de oportunidades e do aumento da eficiência e qualidade das escolas e com vista a "garantir uma educação de qualidade como resposta às novas exigências de uma sociedade do conhecimento e da competitividade" (Edital do PNPSE). Este Programa assenta no princípio de que são

as comunidades educativas quem melhor conhece os seus contextos, as dificuldades e potencialidades, sendo, por isso, quem está melhor preparado para encontrar soluções locais e conceber planos de ação estratégica, pensados ao nivel de cada escola, com o objetivo de melhorar as práticas educativas e as aprendizagens dos alunos. (Preâmbulo da Resolução do Conselho de Ministros n ${ }^{\circ} 23 / 2016$ )

O trabalho desenvolvido nesta área assenta numa "lógica de complementaridade e convergência entre escolas e comunidade" (Costa, 2019, p. 23), já que muitos dos preditores do insucesso se relacionam com os contextos locais.

Ainda no intuito de combater o abandono e o insucesso escolar e de promover a qualidade das aprendizagens, foi aprovado pelo Despacho $\mathrm{n}^{\mathrm{0}} 3721 / 2017$, de 3 de maio, a realização de Projetos-Piloto de Inovação Pedagógica (PPIP), em regime de experiência pedagógica, durante três anos escolares, ou seja, entre os anos letivos 2016/2017 e 2018/2019.

As medidas e estratégias a implementar no âmbito destes projetos situam-se nos seguintes domínios: diversificação e gestão curricular; articulação curricular; inovação pedagógica; organização e funcionamento interno; e relacionamento com a comunidade. (ponto 2 do Despacho $\left.\mathrm{n}^{\circ} 3721 / 2017\right)$

Em termos gerais, todas estas medidas apontam no sentido de as escolas adotarem estratégias promotoras do sucesso educativo de todos os alunos e em ações inovadoras nos domínios pedagógico, curricular 
e organizacional, através da articulação disciplinar, do trabalho interdisciplinar e de interligação com a comunidade.

A "relevância" curricular tem sido apontada como um critério fundamental, quer no plano macropolítico, quer no plano meso e micro das opções curriculares e das metodologias de ensino. A "relevância" curricular é assim entendida como

oposição aos conteúdos disciplinares clássicos, à rotina, à repetição, ao sem sentido de muitas aprendizagens, ao carácter estéril e formalizado que o currículo, seus conteúdos e métodos, carregavam com a tradição da transmissão repetitiva do cânone cultural, preestabelecido, $e$ escassamente contestado, durante muitas décadas, como o único e "natural" domínio curricular legítimo para a escola. (Pacheco et al, 2018, p. 93)

A questão da relevância do currículo assume extrema importância para que a aprendizagem ocorra efetivamente e seja significativa, tornando-se indispensável para a experiência individual e social de cada aluno e para a consequente mobilização útil dos conhecimentos e competências adquiridas através da escola. Segundo Perrenoud (1999) "a trilogia das habilidades - ler, escrever, contar - que fundou a escolaridade obrigatória no século XIX não está mais à altura das exigências da nossa época” (p. 5). Pacheco e outros (2018) acrescentam ainda que "o conhecimento que não é traduzível em usos e não é mobilizável em situações futuras e em contextos diferentes está condenado a um estatuto de esterilidade cognitiva" (p. 94).

Em 2019, foi publicada a Portaria $\mathrm{n}^{\circ} 181 / 2019$, de 11 de junho, que atendendo ao disposto no Decreto-Lei $\mathrm{n}^{\mathrm{o}} 55 / 2018$, e no âmbito da autonomia e flexibilidade curricular,

consagra a possibilidade de ser conferida às escolas uma maior flexibilidade curricular, concretizada numa gestão superior a $25 \%$ das matrizes curriculares-base das ofertas educativas e formativas, com vista ao desenvolvimento de planos de inovação curricular, pedagógica ou de outros domínios. (Preâmbulo da Portaria ${ }^{\circ} 181 / 2019$ )

Atendendo às matrizes curriculares-base das ofertas educativas e formativas dos ensinos básico e secundário, pretende-se que as escolas possam conceber e desenvolver planos de inovação curricular, pedagógica e/ou organizacional, adequados às suas reais necessidades e com vista à inclusão e sucesso de todos os alunos. A implementação dos planos de inovação requer uma gestão superior a $25 \%$ do total da carga horária das matrizes curriculares-base (artigo $2^{\circ}$ ), percentagem essa que, como já referimos, havia sido conferida através do Decreto-Lei $n^{\circ}$ 55/2018 (artigo $12^{\circ}$ ).

Neste sentido, as escolas podem considerar, entre outras, as seguintes possibilidades:

A redistribuição, ao longo de cada ciclo ou nivel de ensino ou ciclo de formação, das disciplinas/módulos/unidades de formação de curta duração (UFCD) e respetivas cargas horárias previstas em cada matriz curricular-base;

A redistribuição dos tempos/horas fixados entre componentes da matriz curricular-base ao longo do ciclo ou nivel de ensino ou ciclo de formação;

A criação de novas disciplinas, através da reafectação de tempos/horas fixados para as disciplinas constantes da matriz curricular-base;

A organização diversa de turmas, grupos de alunos ou de aprendizagem, considerando o número total de turmas por ano de escolaridade ou de formação aprovado na rede de ofertas educativas e formativas;

A gestão interturmas dos tempos/horas fixados nas matrizes curriculares-base, através de distribuição de cargas horárias ao longo do ciclo ou nível de ensino ou ciclo de formação, sem exceder o total da carga horária semanal, quando aplicável. (artigo $4^{\circ}$, ponto 4 , da Portaria $\mathrm{n}^{\circ} 181 / 2019$ )

É ainda atribuída às escolas a possibilidade de adotarem regras próprias na organização do ano escolar (artigo $4^{\circ}$, ponto 5), bem como desenvolverem percursos curriculares alternativos (artigo $4^{\circ}$, ponto $7 \mathrm{e}$ artigo $7^{\circ}$ ). 
As opções curriculares e as medidas de natureza pedagógica, didática e organizacional adotadas pelas escolas devem contribuir para a aquisição e desenvolvimento de conhecimentos, capacidades e atitudes definidas nas áreas de competências do Perfil dos Alunos à Saída da Escolaridade Obrigatória. Por outro lado, pretende-se que estas opções privilegiem uma "gestão curricular contextualizada"; uma "articulação curricular assente na multidisciplinaridade, na interdisciplinaridade e na transdisciplinaridade"; metodologias que incidam na aprendizagem e na avaliação; "dinâmicas pedagógicas" baseadas em "equipas de trabalho docente" e na "cooperação de pais ou encarregados de educação" e restante comunidade educativa (artigo $5^{\circ}$, ponto 2 ).

Com vista a uma melhoria contínua, os planos de inovação das escolas devem ser alvo de uma monitorização regular e de um processo de autoavaliação, de forma a "aferir o impacto das opções e medidas adotadas, como estratégia de melhoria da qualidade das aprendizagens e de promoção do sucesso de todos os alunos" (artigo $8^{\circ}$ ).

Esta Portaria entrou em vigor no ano letivo 2019/2020 e apresentou-se como uma oportunidade de as escolas usufruírem da sua autonomia e criarem projetos curriculares adequados aos contextos e cenários pedagógicos propícios a aprendizagens significativas, rumo ao sucesso educativo e à inclusão de todos os alunos.

\section{Considerações finais}

Em Portugal, a discussão em torno dos conceitos de autonomia da escola e da gestão flexível do currículo surgiram há mais de duas décadas. A política educativa plasmada nos documentos normativos dos últimos quatro anos remete para a valorização e centralidade da escola, dos professores e dos alunos, enquanto ponto de partida para uma gestão flexível e contextualizada do currículo, com vista à criação de uma escola democrática, de qualidade e para todos.

De forma a cumprir este desiderato, o Ministério da Educação Português lançou novos desafios no que se refere à organização escolar, ao currículo e às práticas pedagógicas. Ao nível do discurso jurídico-normativo, preconiza-se que a escola deve assegurar a aprendizagem de todos os alunos, promovendo o desenvolvimento de competências que lhes permitam questionar os saberes estabelecidos, integrar conhecimentos emergentes, comunicar eficientemente e resolver problemas complexos, com vista ao exercício de uma cidadania ativa, informada e consciente. Pretende-se ainda que os alunos sejam empreendedores, responsáveis e estejam preparados para um futuro incerto. Trata-se de incorporar, por um lado, os saberes que são considerados os pilares da educação, ou seja, aprender a conhecer, aprender a fazer, aprender a ser e aprender a viver juntos (UNESCO, 1996) e, por outro, de reconhecer os ensinamentos legados por Freire (2014), tais como a valorização da "curiosidade epistemológica" dos alunos, baseada numa educação problematizadora e no princípio de que “(...) ensinar não é transferir conhecimento, mas criar as possibilidades para a sua produção ou a sua construção” (p. 24).

Exige-se, portanto, uma nova conceção de escola e do currículo - prescrito e oculto. Exige-se maior autonomia para a escola que substancie a potencialidade do território enquanto espaço educador e vislumbre nos seus profissionais de educação atores e autores de uma outra escola possível, mais democrática e inclusiva (Fraga, 2019). Exige-se, igualmente, uma transformação do papel dos professores e dos alunos. As dimensões da autonomia pedagógica e curricular têm de ser (re)equacionadas, enquanto meios promotores de aprendizagens significativas que dotem os alunos de conhecimentos, competências e atitudes imprescindíveis às condições, exigências e desafios do século XXI. Muito embora possamos reconhecer o valor do quadro normativo analisado face ao aprofundamento e desenvolvimento da autonomia pedagógica e curricular, parece-nos necessário uma reflexão maior centrada na autonomia substantiva da escola, mesmo no deambular de um sistema educativo que se rege por modelos de administração desconcentrada, com uma dependência significativa do Estado central. Neste sentido, compartilhamos com Murillo e Krichescky (2015),

Si para cambiar hay que aprender a hacer las cosas de forma diferente, para mejorar es imprescindible una dosis de esperanza y optimismo. Los esfuerzos por innovar en la enseñanza no solo deben estar bien argumentados y fuertemente arraigados a los aprendizajes de los 
estudiantes, sino que además deben embeberse de una firme creencia de que es posible conseguir mejores escuelas para todos. (p. 97)

As limitações deste estudo prendem-se com o facto de o método do estudo de caso apresentar algumas fragilidades ao nível da validade dos resultados alcançados, nomeadamente por não permitir generalizações (Oliveira e Ferreira, 2014; Yin, 2005). Dada a peculiaridade e singularidade do quadro jurídico-normativo em estudo, pretende-se recorrer a uma abordagem predominantemente descritiva, interpretativa e hermenêutica, pelo que não faz sentido qualquer tentativa de generalização ou de extrapolação para outros contextos.

Apesar de, ao nível das intenções declaradas, os diversos documentos de política educativa em Portugal consagrarem a autonomia curricular e pedagógica, é preponderante realizar estudos empíricos que incidam na aplicabilidade desta autonomia no plano das ações, ou seja, nas práticas organizacionais, curriculares e pedagógicas, no sentido de aferir se há lugar para a articulação curricular, se existe a corresponsabilização dos alunos no processo educativo e se são realizadas aprendizagens significativas, numa perspetiva interdisciplinar do conhecimento, que lhes permitam desenvolver conhecimentos, competências e atitudes capazes superar os desafios da globalização e da pós-modernidade.

\section{Referências}

Afonso, N. (2005). Investigação naturalista em educação. Edições ASA.

Apple, M. (2006). Ideologia e currículo. Artmed.

Bauman, Z. (2001). Modernidade líquida. Ed. Zahar.

Bauman, Z. (2007). Tempos líquidos. Jorge Zahar Editor.

Bryman, A. (1988). Quality and quantity in social research. Unwin Hyman.

Carmo, H. e Ferreira, M. M. (1998). Metodologia da investigação. Guia para a auto-aprendizagem. Universidade Aberta.

Cohen, A. e Fradique, J. (2018). Guia da autonomia e flexibilidade curricular. Raiz Editora.

Cosme, A. (2018). Autonomia e flexibilidade curricular: propostas e estratégias de ação-ensino básico: Ensino secundário. Porto Editora.

Costa, J. (2019). Melhores aprendizagens e sucesso escolar. Medidas de política educativa em curso. Em J. C. Morgado, Viana, I. e Pacheco, J. A. (Orgs.), Currículo, inovação e flexibilização (pp. 13-24). De Facto Editores.

Dale, R. (1998). Globalisation: A new world for comparative education? Em J. Schreiwer (Org.), Discourse formation in comparative education (pp. 89-123). Peter Lang. https://doi.org/10.1590/S0101-73302004000200007

Dale, R. (2004). Globalização e educação: Demonstrando a existência de uma "cultura educacional mundial comum" ou localizando uma "agenda globalmente estruturada para a educação"? Educação e Sociedade, 25(87), 423-460.

DGE. (2018). Acompanhamento e monitorização PAFC. DGE.

Fernandes, P. (2011). O currículo do ensino básico em Portugal: Políticas, perspetivas e desafios. Porto Editora.

Flick, U. (2009). Introdução à pesquisa qualitativa. Artmed.

Formosinho, J. (2007). O currículo uniforme pronto-a-vestir de tamanho único. Edições Pedago.

Fortin, M. F. (2009). O processo de investigação. Da concepção à realização. Lusociência.

Fraga, N. (2019). Lideranças pedagógicas em contextos emergentes de autonomia e flexibilidade curricular. Revista Diversidades, 54, 11-15.

Fraga, N. (2020). Recensão crítica da obra: Teodoro, A. (2020). Contesting the Global Development of Sustainable and Inclusive Education. Education Reform and the Challenges of Neoliberal Globalization. Revista Lusófona da Educação, 49, 231-240.

Freire, P. (2014). Pedagogia da autonomia: Saberes necessários à prática educativa. Paz e Terra. 
Goodson, I. (1997). A construção social do currículo. Educa.

Goodson, I. (2001). O currículo em mudança. Estudos na construção social do currículo. Porto Editora.

Leite, C. (2006). Políticas de currículo em Portugal e (im)possibilidades da escola se assumir como uma instituição curricularmente inteligente. Currículo Sem Fronteiras, 6(2), 67-81.

Lessard-Hébert, M., Goyette, G. e Boutin, G. (2008). Investigação qualitativa: Fundamentos e práticas. Instituto Piaget. Lima, L. e Sá, V. (2017). O governo das escolas. Democracia, controlo e performatividade. Edições Húmus.

Lipovetsky, G. e Charles, S. (2018). Os tempos hipermodernos. Edições 70.

Lyotard, J. F. (1989). A condição pós-moderna. Gradiva.

Merriam, S. (1998). Qualitative research and case study applications in education: Revised and expanded from case study research in education. Jossey-Bass Publishers.

Moreira, A. F. e Pacheco, J. A. (2006). Globalização e educação: Desafios para políticas e práticas. Porto Editora.

Morin, E. (1996). O problema epistemológico da complexidade. Europa-América.

Morin, E. (2002). Os sete saberes necessários à educação do futuro. Cortez Unesco.

Murillo, F. J. e Krichescky, G. J. (2015). Mejora de la escuela: Medio siglo de lecciones aprendidas. REICE. Revista Iberoamericana sobre Calidad, Eficacia y Cambio en Educación, 13(1), 69-102.

OCDE. (1997). Education at a glance: OECD indicators. OCDE.

OCDE. (2016a). Global competency for an inclusive world. OCDE.

OCDE. (2016b). The future of education and skills: Education 2030. OCDE.

OCDE. (2018a). Education at a glance. OCDE.

OCDE. (2018b). Curriculum flexibility and autonomy in Portugal, an OECD review. OCDE.

OCDE. (2018c). Preparing ouryouth for an inclusive and sustainable World. The OECD PISA global competence framework. OCDE.

OCDE. (2019). Trends shaping education 2019. OCDE. OCDE.

Oliveira, E. e Ferreira. (2014). Métodos de investigação. Da interrogação à descoberta científica. Vida Económica - Editorial, SA.

Pacheco, J. A., Roldão, M. C. e Estrela, M. T. (Orgs). (2018). Estudos de currículo. Porto Editora.

Pardal, L. e Lopes, E. (2011). Métodos e técnicas de investigação social. Areal Editores.

Perrenoud, P. (1999). Construir competências é virar as costas aos saberes? Pátio. Revista Pedagógica, 11, 15-19.

Rizvi, F. e Lingard, B. (2012). A OCDE e as mudanças globais nas políticas de educação. Em R. Cowen, A. Kazamias e E. Unterhalter. Educação comparada. Panorama internacional e perspectivas (pp. 531-551). UNESCO.

Roldão, M. C. e Almeida, S. (2018). Gestão curricular para a autonomia das escolas e professores. Direção-Geral da Educação.

Roldão, M. C. (2003a). Diferenciação curricular revisitada-conceito, discurso e práxis. Porto Editora.

Roldão, M. C. (2003b). Avaliação de competências e gestão do currículo-as questões dos professores. Editorial Presença.

Roldão, M. C. (2009). Estratégias de ensino-o saber e o agir do professor. Fundação Manuel Leão.

Sousa, A. (2005). Investigação em educação. Livros Horizonte.

Sousa, J. M. e Fino, C. N. (2014). O pecado original do currículo. Em M. J. Carvalho (Coord.). Atas do XII Congresso da SPCE. Espaços de investigação, reflexão e ação interdisciplinar (pp. 1267-1191). UTAD.

Stake, R. (2007). A arte da investigação com estudos de caso. Fundação Calouste Gulbenkian. 
Teodoro, A. (2001). Organizações internacionais e políticas educativas nacionais: A emergência de novas formas de regulação transnacional, ou uma globalização de baixa intensidade (pp. 121-158). Em S. Stoer, L. Cortesão e J. A. Correia (Orgs.). Transnacionalização da educação. Da crise da educação à "educação" da crise (pp. 53-88). Edições Afrontamento.

Teodoro, A. (2012). Novos modos de regulação transnacional das políticas de educação: A regulação pelos resultados e o papel das comparações internacionais. (pp.17-34). Em A. Teodoro e E. Jezine (Orgs.) Organizações internacionais e modos de regulação das políticas de educação. Indicadores e comparações internacionais (pp. 23-41). Liber Livro.

Teodoro, A. (2020). Contesting the global development of sustainable and inclusive education. Education reform and the challenges of neoliberal globalization. Routledge. https://doi.org/10.4324/9781003013686

Tuckman, B. (2000). Manual de investigação em educação. Fundação Calouste Gulbenkian.

UNESCO. (1996). Educação: Um tesouro a descobrir. Relatório para a Unesco da Comissão Internacional sobre educação para o século XXI. Edições ASA.

Varela de Freitas, C. (2019). Flexibilidade curricular em análise: Da oportunidade a uma prática consistente. Em J. C. Morgado, Viana, I. e Pacheco, J. A. (Orgs.). Currículo, inovação e flexibilização (pp. 25-47). De Facto Editores.

Yin, R. (2005). Estudo de caso: Planejamento e métodos. Bookman.

\section{Breve CV dos autores}

\section{Sofia Silva}

Assistente convidada da Faculdade de Ciências Sociais - Departamento de Ciências da Educação da Universidade da Madeira. Técnica Superior de Educação na Secretaria Regional de Educação, Ciência e Tecnologia da Região Autónoma da Madeira. Doutoranda em Currículo e Inovação Pedagógica pela Universidade da Madeira. Mestre em Ciências da Educação, na especialidade de Administração Educacional pela Universidade da Madeira. Licenciada em Ciências da Educação pela Universidade da Madeira. A sua trajetória de investigação centra-se nas seguintes áreas: Currículo; Inovação Pedagógica, Administração Educacional e Liderança Educacional. Email: sofia.silva@staff.uma.pt

ORCID ID: https://orcid.org/0000-0002-4649-307X

\section{Nuno Fraga}

Professor Auxiliar na Faculdade de Ciências Sociais - Departamento de Ciências da Educação da Universidade da Madeira. Doutor em Educação pela Universidade Lúsofona de Humanidades e Tecnologias de Lisboa. Diretor do Centro de Investigação em Educação da Universidade da Madeira. Diretor do Curso de Mestrado em Ciências da Educação - Administração Educacional da Universidade da Madeira. A sua trajetória de investigação centra-se nos seguintes domínios ou campos de análise: Administração Educacional; Liderança Educacional; Educação e Desenvolvimento Comunitário Local; Paulo Freire. Email: nfraga@staff.uma.pt

ORCID ID: https://orcid.org/0000-0002-3382-6357 